\title{
Separation of Molybdenum(VI) and Uranium(VI) through Supported Liquid Membrane Containing $\alpha$-Hydroxy Oxime as a Mobile Carrier
}

\author{
Mohamed H. H. MAHMOUD", Shigeto NAKAMURA ${ }^{* *}$ and Kenichi AKIBA ${ }^{\dagger}$ \\ Institute for Advanced Materials Processing, Tohoku University, Sendai 980-77, Japan
}

\begin{abstract}
The solvent extraction of molybdenum(VI) and uranium(VI) with $\alpha$-hydroxy oxime, 5,8diethyl-7-hydroxydodecan-6-one oxime (LIX 63) and their stripping behavior have been investigated. A cationic species of $\mathrm{Mo}(\mathrm{VI})$ was preferentially extracted in an acidic region, and the extraction was greatly depressed above pH 4. Uranium(VI) species were extracted in a nearly neutral region and selectively stripped with a dilute acid. The transport of these metal complexes across a supported liquid membrane (SLM) has been investigated employing LIX 63 as a mobile carrier: Uranium(VI) was selectively transported on the product side, while Mo(VI) species was retained in the SLM in the low $\mathrm{pH}$ region and remained in the feed solution in the nearly neutral region. This improves their mutual separation, and only U(VI) was recovered in the product solution, depressing the transport of $\mathrm{Mo}(\mathrm{VI})$.
\end{abstract}

Keywords Molybdenum, uranium, solvent extraction, liquid membrane transport, LIX 63, separation

Uranium(VI) is usually accompanied by molybdenum(VI) and other metals in natural resourses. ${ }^{1}$ Separation of U(VI) from Mo(VI) is of importance for attainment of the final products of high purity. The solvent extraction of $\mathrm{Mo}(\mathrm{VI})$ and $\mathrm{U}(\mathrm{VI})$ from acidic solutions has been investigated using a variety of extractants such as tertiary amines, alkylphosphates and sulfoxides. ${ }^{2,3}$

A chelating extractant, $\alpha$-hydroxyl oxime (LIX 63), is useful in the extraction of cationic species, and it has been employed for the extraction of Mo(VI) from acidic solutions. ${ }^{4,5}$ In our previous works, Mo(VI) was effectively extracted with LIX 63 from an acidic region, in which Mo(VI) forms an

*Present address: Central Metallurgical Res. Develop. Inst., Helwon, Cairo, Egypt.

**Present address: Hachinohe National College of Technology, Hachinohe 039-11, Japan.

+ To whom correspondence should be addressed. extractable cationic species of $\mathrm{MoO}_{2}{ }^{2+6,7}$ while uranium(VI) was extracted in a weakly acidic region. ${ }^{8}$

Owing to superior extraction and stripping characteristics, LIX 63 is also available for a mobile carrier to transport metal species through liquid membranes. The transport of U(VI) has been achieved across a supported liquid membrane impregnated with LIX 63, and $U(V I)$ was effectively concentrated by uphill transport. ${ }^{9}$ The successive transport of Mo(VI) was accomplished through the double liquid membranes containing different kinds of carriers, LIX 63 for cationic species and trioctylmethyl ammonium chloride (TOMAC) for anionic species.'

In this work, the extraction of Mo(VI) and U(VI) with LIX 63 and their stripping behavior have been investigated. A supported liquid membrane employing LIX 63 as a mobile carrier has been demonstrated for the separation of $U(V I)$ from Mo(VI) by the selective transport of $U(V I)$. 


\section{Experimental}

\section{Liquid-liquid extraction}

5,8-Diethyl-7-hydroxydodecan-6-one oxime (LIX 63; Henkel) was diluted with kerosene (Wako Pure Chemical Ind.). An aqueous solution containing $10 \mathrm{ppm}$ of each Mo(VI) and $U(V I)$ was shaken with an equal volume of LIX 63 solution at $25^{\circ} \mathrm{C}$. The aqueous $\mathrm{pH}$ was controlled with $\mathrm{H}_{2} \mathrm{SO}_{4}, 0.01 \mathrm{M}(=\mathrm{mol}$ $\left.\mathrm{dm}^{-3}\right)(\mathrm{H}, \mathrm{Na}) \mathrm{CH}_{3} \mathrm{COO}$ or $0.01 \mathrm{M} \mathrm{NH}_{4}$ $(\mathrm{OH}, \mathrm{Cl})$. The concentrations of metals in the aqueous phase were determined by ICP-AES with a SEIKO SPS 1200 A spectrometer.

\section{Liquid membrane transport}

A PTFE membrane (POREFLON FP-045; Sumitomo Electric Ind.) was used as an inert support, which has a thickness of $80 \mu \mathrm{m}$, a porosity of $74 \%$, an average pore size of 0.45 $\mu \mathrm{m}$ and an area of $26 \mathrm{~cm}^{2}$. The liquid membrne impregnated with LIX 63 in kerosene was contacted with a feed solution $\left(100 \mathrm{~cm}^{3}\right)$ containing $10 \mathrm{ppm}$ of each $\mathrm{Mo}(\mathrm{VI})$ and $U(V I)$ and an equal volume of a stripping product solution. Transport experiments were carried out in a similar manner described in the previous paper. ${ }^{9}$ Concentrations of metals in the feed and product solutions were measured by ICP-AES at selected intervals.

\section{Results and Discussion}

Liquid-liquid extraction of $M o(V I)$ and $U(V I)$ Extraction of Mo(VI) and U(VI) with LIX 63 from a dilute sulfuric acid solution was examined by varying contact time. As Fig. 1 shows, the extraction of Mo(VI) was fairly fast and Mo(VI) was completely removed from the aqueous phase after $1 \mathrm{~min}$. The extraction of $U(V I)$ more slowly increased. Their mutual separation is likely performed by preferential extraction of Mo(VI) in a short contact time.

As Fig. 2 shows, the extraction of Mo(VI) increased with LIX 63 concentration up to $0.05 \mathrm{M}$ and became quantitative at higher concentrations, while no extraction of U(VI) occurred below $0.1 \mathrm{M}$ LIX 63 .

Several forms of $\mathrm{Mo}$ (VI) are present in aqueous solutions and $\mathrm{MoO}_{2}{ }^{2+}$ is a predominant species below $\mathrm{pH} 2$, while U(VI) exists in cationic species in a wide $\mathrm{pH}$ region.

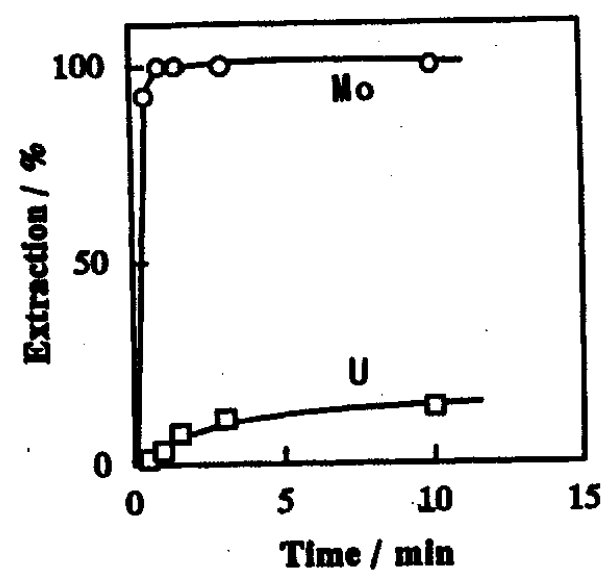

Fig. 1 Extraction with $0.1 \mathrm{M}$ LIX 63 in kerosene from $0.01 \mathrm{M} \mathrm{H}_{2} \mathrm{SO}_{4}$.

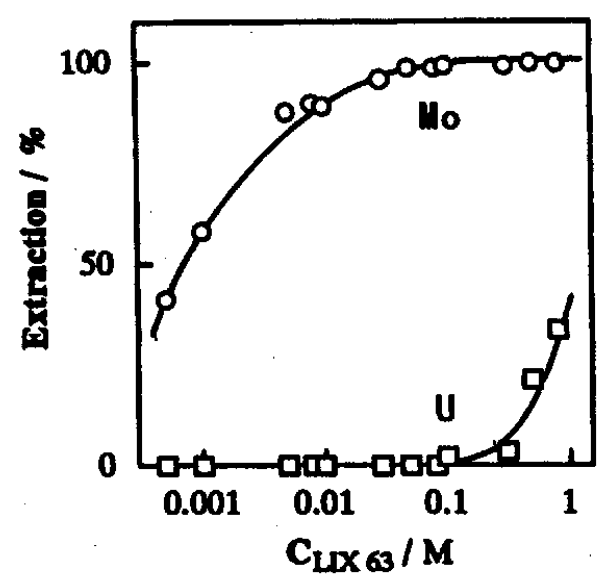

Fig. 2 Effect of LIX 63 concentration on the extraction from $0.01 \mathrm{M} \mathrm{H}_{2} \mathrm{SO}_{4} .1 \mathrm{~min}$.

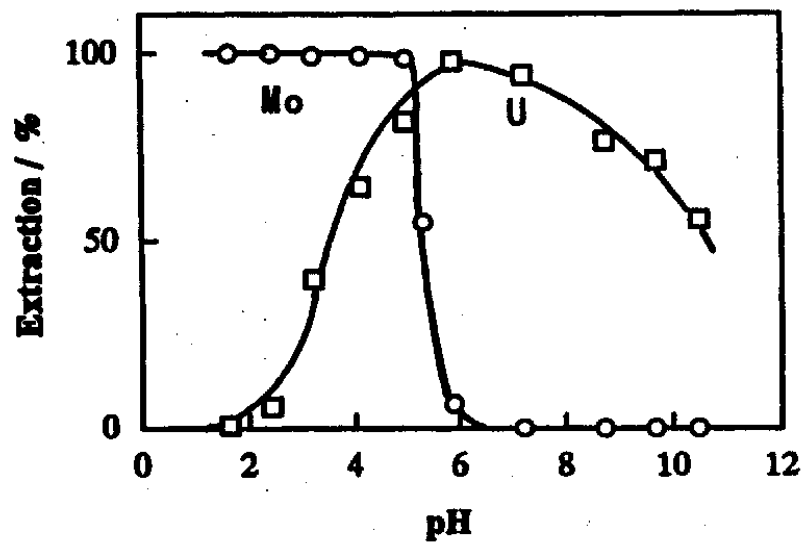

Fig. 3 Effect of $\mathrm{pH}$ on the extraction with 0.01 M LIX 63. $10 \mathrm{~min}$. 
The extraction of these cationic species proceeds as follows, 6,8

$\mathrm{MO}_{2}^{2+}+2 \mathrm{HL}(\mathrm{o}) \rightleftarrows \mathrm{MO}_{2} \mathrm{~L}_{2}(\mathrm{o})+2 \mathrm{H}^{+}$

where $M$ represents $M o(V I)$ or $U(V I), H L$ represents LIX 63 and the subscript (o) refers to the organic phase.

Chemical species of these metal ions were complicated depending on an aqueous acidity, and extraction behavior was investigated by varying the $\mathrm{pH}$. The extraction of $\mathrm{Mo}$ (VI) was effective in an acidic region and sharply fell down above $\mathrm{pH}$ 5 due to the formation of an unextractable anionic $\mathrm{MoO}_{4}{ }^{2-}$ species, as shown in Fig. 3. The extraction of U(VI) increased with increasing $\mathrm{pH}$ above 2 and attained $a$ maximum around $\mathrm{pH} 6$. In higher $\mathrm{pH}$ regions, the U(VI) extraction gradually decreased due to the presence of the hydrolyzed forms. Though the extraction separation of Mo(VI) from $U(V I)$ was successful in the low $\mathrm{pH}$ region, the selective extraction of $U(V I)$ above pH 6 is also promising.
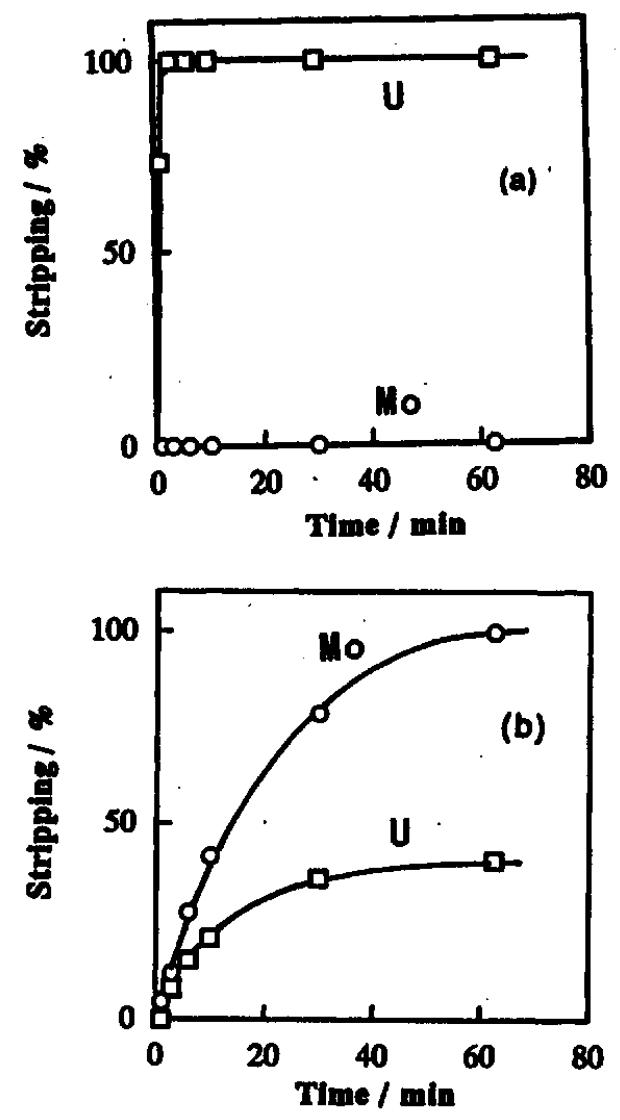

Fig. 4 Stripping with (a) $0.1 \mathrm{M} \mathrm{H}_{2} \mathrm{SO}_{4}$ and

(b) $0.05 \mathrm{M} \mathrm{NaOH}$. Extraction:0.01 M LIX 63, pH 5.5, $10 \mathrm{~min}$.

\section{Selective stripping}

Appropriate aqueous conditions are of importance for selective stripping of the desired metal ion. After Mo(VI) and U(VI) had been firstly extracted from pH 5.5 for 10 min, stripping was tested by using prospective agents. As Fig. 4(a) shows, U(VI) was selectively stripped into $0.1 \mathrm{M} \mathrm{H}_{2} \mathrm{SO}_{4}$ after $3 \mathrm{~min}$, while Mo(VI) remained in the organic phase. As Fig. 4(b) shows, Mo (VI) was nearly completely stripped with $0.05 \mathrm{M}$ $\mathrm{NaOH}$ after $1 \mathrm{~h}$, but $40 \%$ of U(VI) was stripped together.
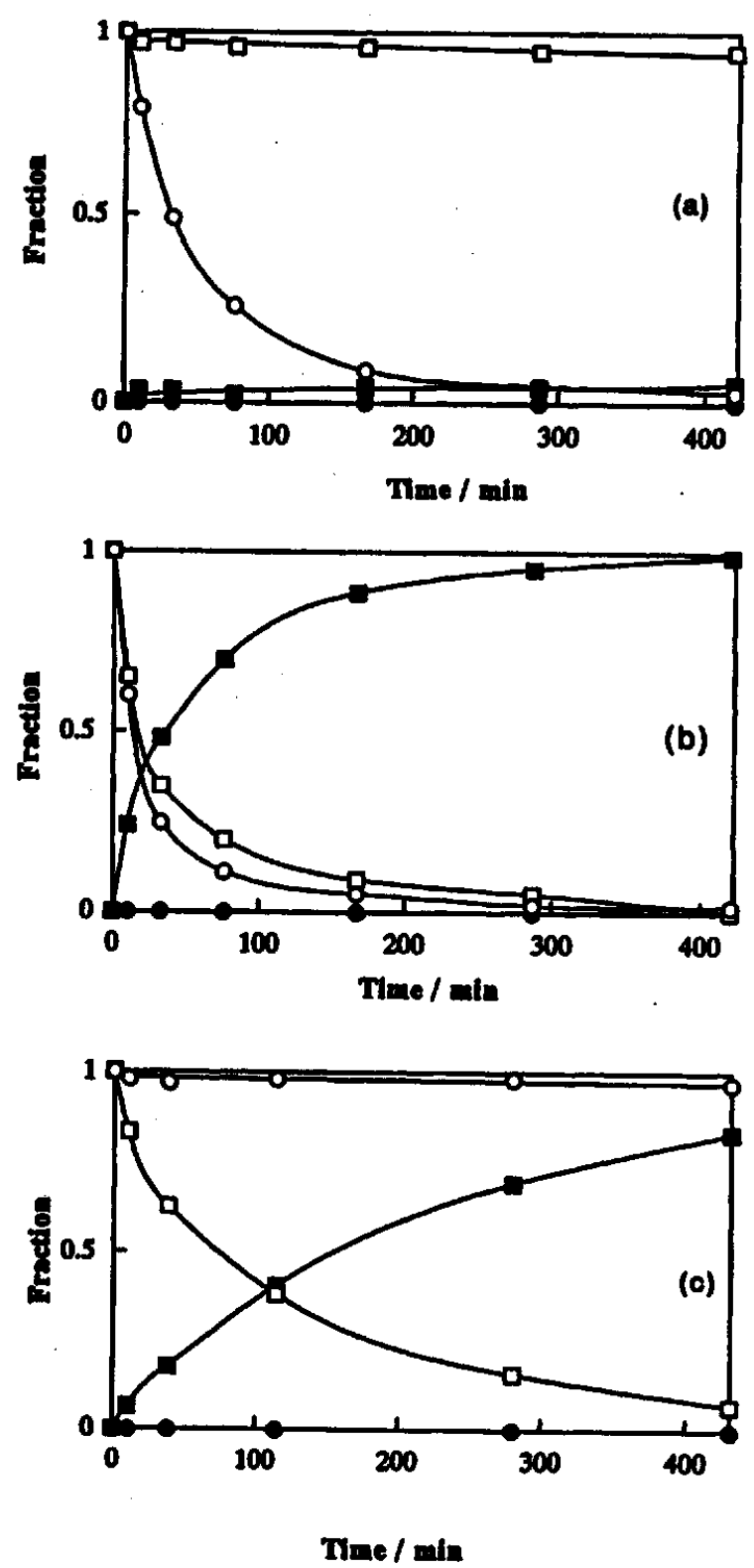

Fig. 5 Transport through $0.1 \mathrm{M}$ LIX 63-SLM. Feed (open): (a) pH 2.2, (b) 4.6, (c) 6.9; Product (filled): $0.1 \mathrm{M} \mathrm{H}_{2} \mathrm{SO}_{4}$. $(\mathrm{O}, \mathrm{O}) \mathrm{Mo}$, $(\square, \square)$ U. 
Transport separation through LIX 63-SLM

Based on the extraction and stripping behavior of individual metal species, SLM transport experiments were performed using LIX 63 as a mobile carrier. The transport of Mo(VI) and U(VI) was investigated by varying the $\mathrm{pH}$ of the feed solution. For selective stripping of $\mathrm{U}(\mathrm{VI}), 0.1 \mathrm{M} \mathrm{H}_{2} \mathrm{SO}_{4}$ was used as a product solution.

Figure 5 shows typical transport profiles of each metal ion against shaking time. At a low $\mathrm{pH}$ of 2.2 (Fig. 5 (a)), Mo(VI) was removed from the feed solution and retained as the complex with LIX 63 in the SLM phase, while U(VI) was poorly extracted and remained in the feed side. As the feed $\mathrm{pH}$ increased to 4.6 (Fig. 5(b)), the both metal ions were removed from the feed solution, and only U(VI) was selectively transported to the product side. The Mo(VI) species retained in SLM can be removed by washing with an alkaline solution such as $0.1 \mathrm{M}$ $\mathrm{NaOH}$ after the transport experiments. At a neutral pH 6.9 (Fig. 5(c)), U(VI) was transported into the product side, while Mo(VI) remained in the feed side. The transport of metal species thus proceeded in accordance with the solvent extraction behavior mentioned above.

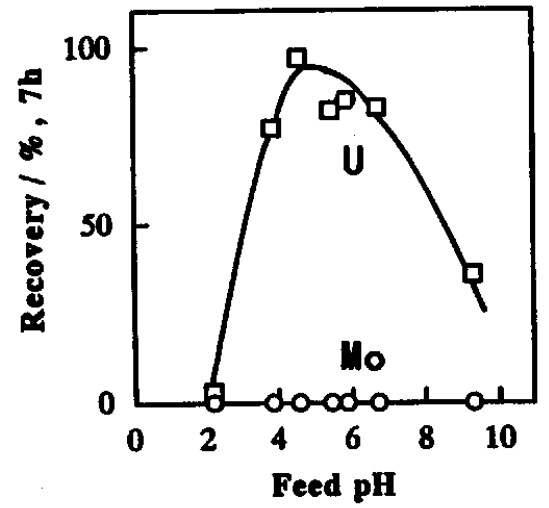

Fig. 6 Effect of $\mathrm{pH}$ on the recovery in the product side.
Figure 6 shows the effect of the pH of the feed solution on the recovery in the product solution. The recovery of $U(V I)$ increased with increasing $\mathrm{pH}$ up to about 6 and then gradually decreased at higher $\mathrm{pH}$ values owing to the suppression of extraction from the feed solution. No portion of Mo(VI) passed through the membrane to the product side and the separation of $U(V I)$ from Mo(VI) was successfully achieved.

\section{References}

1. R. C. Merritt "The Extractive Metallurgy of Uranium," Colorado School of Mines Res. Inst.,1971, p. 137.

2. W. C. Babcock, D. T. Friesen and E. D. Lachapelle, J. Membrane Sci., 26, 303 (1986).

3. P. Behera, R. Mishra and V. Chakravortty, Radiochim. Acta, 62, 153 (1993).

4. M. Sano, J. Shibata, M. Harada and S. Nishimura, J. Min. Metall. Inst. Japan, 104, 475 (1988).

5. A. Trujillo and H. Freiser, Solvent Extr. Ion Exch., 7, 1 (1989).

6. M. H. H. Mahmoud, S. Nakamura and K. Akiba, Solvent Extr. Ion Exch., 14, 203 (1996).

7. M. H. H. Mahmoud, S. Nakamura and K. Akiba, Sep. Sci. Technol., 32, 1739 (1997).

8. K. Akiba and T. Kanno, Solvent Extr. Ion Exch., 1, 729 (1983).

9. K. Akiba and T. Kanno, Sep. Sci. Technol., 18, 831 (1983). 